\title{
Pressures to adhere to treatment ('leverage') in English mental healthcare ${ }^{\dagger}$
}

Tom Burns, Ksenija Yeeles, Andrew Molodynski, Helen Nightingale, Maria Vazquez-Montes, Kathleen Sheehan and Louise Linsell

\section{Background}

Coercion has usually been equated with legal detention. Non-statutory pressures to adhere to treatment, 'leverage', have been identified as widespread in US public mental healthcare. It is not clear if this is so outside the USA.

\section{Aims}

To measure rates of different non-statutory pressures in distinct clinical populations in England, to test their associations with patient characteristics and compare them with US rates.

\section{Method}

Data were collected by a structured interview conducted by independent researchers supplemented by data extraction from case notes.

\section{Results}

We recruited a sample of 417 participants from four differing clinical populations. Lifetime experience of leverage was reported in $35 \%$ of the sample, $63 \%$ in substance misusers, $33 \%$ and $30 \%$ in the psychosis samples and $15 \%$ in the non-psychosis sample. Leverage was associated with repeated hospitalisations, substance misuse diagnosis and lower insight as measured by the Insight and Treatment Attitudes Questionnaire. Housing leverage was the most frequent form (24\%). Levels were markedly lower than those reported in the USA.

\section{Conclusions}

Non-statutory pressure to adhere to treatment (leverage) is common in English mental healthcare but has received little clinical or research attention. Urgent attention is needed to understand its variation and place in community practice.

\section{Declaration of interest}

None.
Compulsory treatment is integral to mental healthcare and originally restricted to in-patient settings. ${ }^{1}$ Several legislations now permit coerced treatment in the community. ${ }^{2}$ Many 'voluntary' patients experience their cooperation with mental healthcare as coerced. ${ }^{3}$ A study of public mental health service patients in five US cities found that half the sample reported experiencing specific pressures to promote treatment adherence. ${ }^{4}$ These pressures are referred to as 'informal coercion' or more commonly 'leverages'. Leverages included access to accommodation, financial assistance and reduction or waiving of judicial sanctions. It is not clear if these high levels of leverage are restricted to the USA. The US mental healthcare system has a relatively fragmented community provision, limited availability of adequate benefits ${ }^{5}$ and some availability of 'mental health courts.' Leverage may be less common in a European setting where accommodation and welfare payments are basic entitlements and cannot be easily linked to treatment. We measured the prevalence and patterns of leverage across four differing clinical samples and tested for patient and treatment characteristics associated with them.

\section{Method}

Ethical approval was given by Oxfordshire Research Ethics Committee A (22 February 2006, Ref. No. 05/Q1604/180). An independent researcher explained the study and obtained written informed consent for an interview and examination of case notes. Participants were paid $£ 10$ (US\$15) for the 50 min interview. This comprised demographic and historical data plus a series of structured questions (Appendix) on four forms of leverage adapted from Monahan and colleagues' US study. ${ }^{4}$

TSee editorial, pp. 90-91, this issue.

\section{Sample}

Participants were recruited from the Oxford and Buckinghamshire Mental Health Trust that serves a mixed urban and rural population of 1 million. Recruitment procedures varied between the different teams. We aimed to recruit 100 assertive outreach team (AOT) patients with a diagnosis of psychosis, 100 community mental health team (CMHT) patients with a diagnosis of psychosis, 100 CMHT patients with a diagnosis of non-psychosis and lastly 100 people with heroin-dependent substance misuse currently treated with substitution medication (methadone or subutex). There were no exclusion criteria apart from a duration of care of less than 6 months.

Assertive outreach teams target hard to engage people with psychosis and have small case-loads (1:12), whereas CMHTs have higher, diagnostically mixed case-loads (usually 1:25). The participants with substance misuse either attended dispersed local clinics run by the mental health services or attended their general practitioner as 'shared-care' patients for prescribing and follow-up.

All patients on the case-loads of the Trust's four AOTs were approached and CMHT participants were recruited in randomly selected blocks of 25 with either psychosis or non-psychosis diagnoses from the case-loads of eight teams. Oversampling was undertaken in all four samples because the duration of contact (required to confirm eligibility) could not always be identified reliably from the case notes. Comprehensive case-loads were not available in the substance misuse services. A consecutive convenience sample was obtained from the four methadone clinics in the Oxfordshire County and the Oxford City shared-care methadone services.

A series of established, validated questionnaires and rating instruments were conducted by the researcher at the interview between January 2008 and April 2009. Training was provided by an experienced psychiatrist for the clinical rating scales. The first 
20 participants were jointly rated by both researchers. Interrater reliability for Global Assessment of Functioning $(\mathrm{GAF})^{7}$ was fair (intraclass correlation coefficient $(\mathrm{ICC})=0.489$ ) and for Brief Psychiatric Rating Scale $(\mathrm{BPRS})^{8}$ was moderate $(\mathrm{ICC}=0.789)$. Refresher sessions were conducted every 6 months.

\section{Instruments}

(a) The GAF rates impairment in functioning ranging from 0 to 100 , with given anchors at 10 -point levels.

(b) $\mathrm{BPRS}^{8}$ rates 18 symptoms each for severity from one to seven.

(c) The Insight and Treatment Attitudes Questionnaire (ITAQ) ${ }^{9}$ is a self-reported, semi-structured 11-item questionnaire assessing awareness of illness and need for treatment.

(d) The Conjoint $\mathrm{CAGE}^{10}$ is an 8-item questionnaire for screening both alcohol (four items) and drug misuse (four items). Two or more positive responses on either scale indicate pathology.

(e) Leverage questions are detailed in the Appendix and are taken from the Monahan study. ${ }^{4}$ Questions test for both access to and potential withdrawal of benefits. Questions are repeated for each stage of the criminal justice system. Any positive response within a specific leverage area counts as 'reported'.

\section{Statistical analysis}

Comparisons across three or more sample groups were carried out using Kruskall-Wallis non-parametric tests. A variety of tests were used when only two groups were compared. These were: the Mann-Whitney test for non-normally distributed continuous variables; chi-squared test for binary variables; and ANOVA for categorical variables. To compare our outcomes with the US sample, overall percentages and pooled means and standard deviations were calculated for the latter. A $t$-test was used when comparing means and a two-proportion $Z$-test when comparing percentages. Analyses were run in SPSS 15.0 for Windows.

Univariate and multivariate multilevel logistic regressions were used to investigate the association of sociodemographic and clinical characteristics with types of leverage in the whole sample. As the sample comprised participants from four different groups, it was treated as a stratified sample with two levels or strata. The four subgroups occupy the upper level and the participants form the lower level. It is expected that participants in the same sample group are more similar to each other, thus breaking the independence assumption needed for standard statistical methods. Multilevel models were used to analyse variables measured at different levels simultaneously, employing a statistical model that includes the various dependencies. ${ }^{11}$ Stata 9.0 command xtlogit on Windows was used for this analysis.

\section{Results}

We recruited 417 participants: 101 in the CMHT psychosis group, 101 in the substance misuse group, 102 in the AOT (with psychosis) group and 113 in the CMHT non-psychosis group. Of 912 identified patients, 308 were uncontactable, discharged or ineligible. Of the 604 approached 188 refused involvement.

\section{Baseline characteristics}

Table 1 outlines the sociodemographic and main historical and clinical features of the four samples using the same presentation format and variables as Monahan and colleagues ${ }^{4}$ for ease of comparison. The group was predominantly male $(60 \%)$, White $(89 \%)$ and born in the UK $(89 \%)$. Most patients were single
$(60 \%)$ and most $(83 \%)$ lived in independent accommodation. Service contact ranged from a mean of 17 years for the AOT group to 11.5 years for the substance misuse group with repeated hospitalisations in the mental illness sample (AOT and CMHT groups combined). The BPRS mean total score of 33.0 and GAF of 56.9 indicate a relatively poorly functioning group.

\section{Differences in baseline characteristics between the clinical samples}

There were statistically significant differences between the four clinical samples on a number of variables not included in Table 1. General education was shorter in the substance misuse group; employment was lowest in the AOT group who also were much more likely to be single. The proportion of those with children under 18 who were living with them was lowest in the AOT group at $15 \%$ in contrast to $65 \%$ of those in the CMHT non-psychosis group and 54\% of those in the CMHT psychosis group. The number of past hospitalisations ranged from a mean of 6.5 in the AOT group to 0.2 in the substance misuse group.

\section{Differences between the mental illness and substance misuse samples}

The substance misuse sample appears to have contributed most to the variation in baseline characteristics and so it was compared individually with the mental illness group. The substance misuse sample was significantly younger than the mental illness sample (mean 34.7 v. 42.0 years) with more men $(76 \% v .55 \%)$ and fewer participants from ethnic minorities (3\% v. 13\%). Significant differences were found for all psychiatric history variables. Age at first contact with psychiatric services was significantly lower for the substance misuse group (mean 23.3 v. 25.9), number of psychiatric hospitalisations was lower (mean 0.2 v. 4.0) and number of previous involuntary hospitalisations lower $(4 \% v$. $52 \%)$. The substance misuse sample had more criminal convictions $(82 \%$ v. $26 \%)$ and previous imprisonments (48\% v. $14 \%)$.

\section{Differences within the mental illness groups}

The three mental illness groups (AOT and CMHTs) demonstrated greater homogeneity. There were no significant differences in years of general education, proportion of those with children younger than 18 years and proportion with criminal convictions. All other differences identified across the four samples retained their significance.

\section{Lifetime experience of leverage}

Table 2 displays the rates of lifetime experience of reported leverage types across the four groups. Overall, 145 (35\%) participants reported any leverage, of whom $51(12 \%)$ reported more than one type and seven more than two. Multiple leverages are predominantly reported in the substance misuse group (33\%). Housing leverage is by far the most common (24\%). The criminal justice system leverage of $15 \%$ overall is accounted for almost entirely by the substance misuse and AOT groups. Financial leverage was only reported by ten participants $(2 \%)$ but childcare access leverage was reported for $34(8 \%)$ participants; reflecting $26 \%$ of the 130 with children under 18 years of age.

Table 3 shows the univariate associations of individual leverages and Table 4 the univariate and multivariate associations of overall experience of leverages and of the experience of more than one type of leverage. In multivariate analysis all the significances are lost apart from ethnicity. Reporting more than one type of leverage (Table 4) remains significantly associated in 


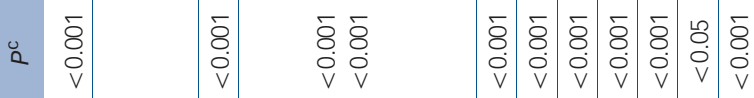
$\frac{\sqrt{0}}{\frac{\pi}{5}}=$

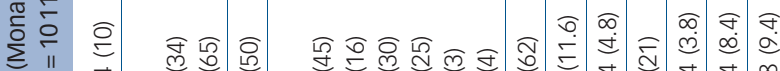
¿II

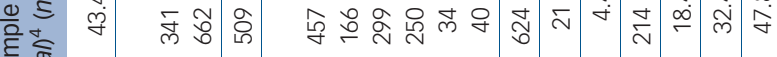
管

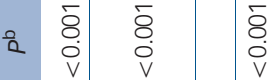

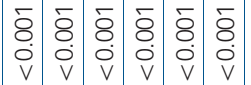

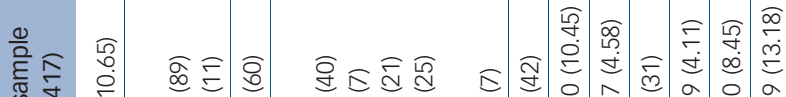

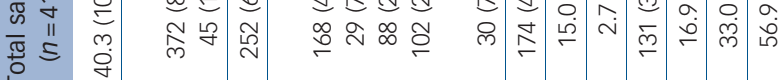

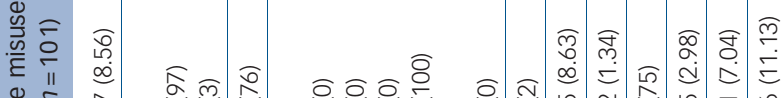

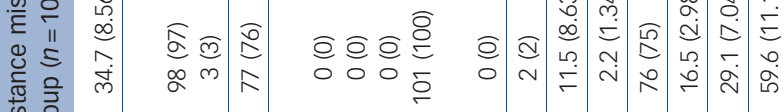
色 항

党

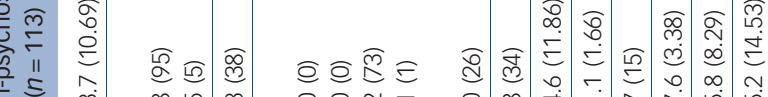

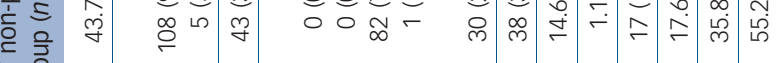
㐍

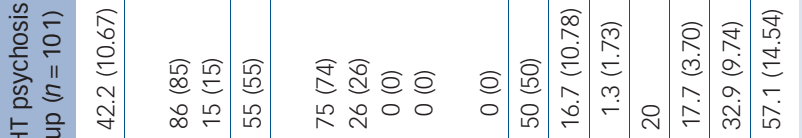

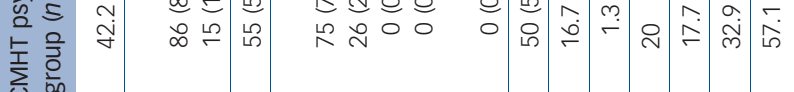
离

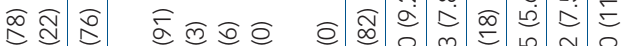
$\infty \pi$ a

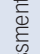


multivariate analysis for independent accommodation, substance misuse diagnosis and a history of imprisonment.

\section{Discussion}

\section{England-USA differences}

This is the first study of leverage in England and demonstrates that it is common in public mental health services for severely ill patients. A third reported feeling coerced to adhere to treatment at some time in their lives. These levels are substantially lower than those from the USA (35\% compared with 51\%). This difference is more pronounced when childcare and access leverage is removed (overall leverage 31\% of English participants, 9\% with more than one form) as this was not reported in the US reference paper, although it has been reported subsequently from the same sample. ${ }^{13}$ Formal coercion in the community was available in the USA but not in the English context at the time of the study. It was experienced by $12-20 \%$ of the US sample ${ }^{4,14}$ but, as it is formal coercion, is not included in our comparison with the US study.

\section{Clinical group differences}

Leverage varied considerably across the clinical groups in the manner anticipated. The younger, substance misuse group reported the highest level of leverage; higher than the US group (63\% compared with 51\%). Levels fell according to the general severity of the groups through the psychosis groups to the non-psychosis CMHT group.

\section{Types of leverage}

The highest rate of leverage was related to accommodation. A quarter of the sample reported this (32\% in the USA). It was substantially higher in the substance misuse group (44\%), presumably reflecting the practice of many landlords (both private and public sector) of demanding attendance at drug programmes as a condition of tenancy. This is much less common in mental illness services, particularly in private accommodation. The $20 \%$ rate found in participants with psychosis is restricted to hostel and supervised accommodation. We found evidence of leverage by private landlords in the mental illness samples.

\begin{tabular}{|c|c|c|c|c|}
\hline & $\begin{array}{l}\text { Housing leverage } \\
\text { OR }(95 \% \mathrm{Cl})\end{array}$ & $\begin{array}{l}\text { Financial leverage } \\
\text { OR }(95 \% \mathrm{Cl})\end{array}$ & $\begin{array}{l}\text { Leverage through criminal } \\
\text { justice, OR }(95 \% \mathrm{Cl})\end{array}$ & $\begin{array}{l}\text { Childcare leverage } \\
\text { OR }(95 \% \mathrm{Cl})\end{array}$ \\
\hline Ethnicity, White & $0.8(0.3-1.8)$ & - & $0.1^{* *}(0.03-0.5)$ & $0.3(0.1-1.2)$ \\
\hline Marital status, single $v$. others & $1.8^{*}(1.1-3.1)$ & $5.7(0.3-114.8)$ & $0.8(0.2-2.5)$ & $1.6(0.7-3.5)$ \\
\hline If children under 18 years, they live: with a separated partner & $2.6^{*}(1.04-6.4)$ & - & $0.2(0.02-2.0)$ & $1.9(0.8-4.6)$ \\
\hline Accommodation, independent $v$. other & $0.3^{* * *}(0.2-0.6)$ & $1.2(0.2-8.7)$ & $1.4(0.5-4.2)$ & $0.9(0.3-2.3)$ \\
\hline If independent, live with: alone $v$. other & $1.2(0.7-2.1)$ & $3.1(0.1-125.3)$ & $0.1 *(0.03-0.7)$ & $1.3(0.5-3.4)$ \\
\hline \multicolumn{5}{|l|}{ Diagnosis (ICD-10) (compared with those with schizophrenia) } \\
\hline Bipolar disorder & $0.4(0.1-1.4)$ & $4.9 \times 10^{-13}(0-\infty)$ & $1.1(0.1-13.8)$ & $1.9(0.4-10.3)$ \\
\hline Major depression & $0.5(0.2-1.1)$ & $4.3 \times 10^{-13}(0-\infty)$ & $2.1 \times 10^{12}(0-\infty)$ & $0.6(0.2-1.9)$ \\
\hline Substance misuse & $2.7^{\star * *}(1.5-4.6)$ & $9.0(0.8-100.2)$ & $2.3(0.8-6.6)$ & $1.2(0.5-3.3)$ \\
\hline Other diagnosis & $0.4(0.1-1.4)$ & $4.3 \times 10^{-13}(0-\infty)$ & $2.1 \times 10^{12}(0-\infty)$ & $2.4 \times 10^{-13}(0-\infty)$ \\
\hline Age at first contact with psychiatric services & $0.5 *(0.3-0.9)$ & $0.6(0.1-3.5)$ & $0.8(0.3-2.2)$ & $0.5(0.2-1.1)$ \\
\hline Number of out-patient visits in the past month & $1.1(0.7-2.0)$ & $1.2(0.2-10.0)$ & $0.2^{*}(0.04-0.9)$ & $1.3(0.6-2.9)$ \\
\hline CAGE: positive for drug or alcohol & $1.80 *(1.0-3.2)$ & $2.50(0.46-13.65)$ & $1.03(0.27-3.91)$ & $1.52(0.69-3.37)$ \\
\hline
\end{tabular}

\begin{tabular}{|c|c|c|c|c|}
\hline & \multirow{2}{*}{$\begin{array}{c}\text { Univariate } \\
\text { Any leverage } \\
\text { OR }(95 \% \mathrm{Cl})\end{array}$} & \multicolumn{3}{|c|}{ Multivariate } \\
\hline & & $\begin{array}{l}\text { More than one type of } \\
\text { leverage, OR }(95 \% \mathrm{Cl})\end{array}$ & $\begin{array}{l}\text { Any leverage } \\
\text { OR }(95 \% \mathrm{Cl})\end{array}$ & $\begin{array}{l}\text { More than one type of } \\
\text { leverage, OR }(95 \% \mathrm{Cl})\end{array}$ \\
\hline Children under 18 years old, yes & $1.4(0.9-2.2)$ & $1.9 *(1.0-3.5)$ & - & $1.5(0.7-2.8)$ \\
\hline Accommodation, independent $v$. other & $0.4^{* *}(0.2-0.7)$ & $0.4^{\star *}(0.2-0.8)$ & $0.53(0.3-1.0)$ & $0.5^{*}(0.2-0.9)$ \\
\hline \multicolumn{5}{|c|}{ Diagnosis (ICD-10) (compared with those with schizophrenia) } \\
\hline Bipolar disorder & $0.5(0.2-1.2)$ & $1.0(0.2-4.5)$ & $0.82(0.3-2.5)$ & $1.4(0.3-6.8)$ \\
\hline Major depression & $0.4^{* *}(0.2-0.7)$ & $1.0(0.3-2.6)$ & $0.6(0.3-1.3)$ & $1.2(0.4-3.5)$ \\
\hline Substance misuse & $3.0^{* * *}(1,8-5,1)$ & $6.2 * * *(3.0-12.8)$ & $5.7 * * *(2.2-15.1)$ & $3.0 *(1.3-7.2)$ \\
\hline Other diagnosis & $0.5(0.2-1.4)$ & $0.4(0.1-3.6)$ & $0.7(0.2-2.3)$ & $0.5(0.1-4.3)$ \\
\hline Age at first contact with psychiatric services & $0.5^{* \star}(0.3-0.8)$ & $0.5(0.3-1.0)$ & $0.6(0.4-1.0)$ & - \\
\hline More than two hospitalisations & $3.3^{* * *}(1.8-6.0)$ & $2.6(0.9-6.9)$ & $2.8^{* *}(1.4-5.6)$ & - \\
\hline Hospitalisations ever & $1.8^{*}(1.1-3.0)$ & $1.5(0.6-3.5)$ & $1.1(0.6-2.3)$ & - \\
\hline Duration of psychiatric history, years & $1.9 * *(1.2-2.9)$ & $1.9(0.98-3.5)$ & $1.3(0.8-2.2)$ & - \\
\hline Criminal convictions ever, yes/no & $2.5^{\star \star *}(1.6-4.1)$ & $3.2^{* *}(1.5-6.8)$ & $1.4(0.7-2.6)$ & $1.4(0.6-3.4)$ \\
\hline Imprisonment ever, yes/no & $2.7^{\star * *}(1.6-4.6)$ & $3.4^{* * *}(1.7-6.7)$ & $1.8(0.9-3.7)$ & $2.4^{*}(1.1-5.2)$ \\
\hline ITAQ total score & $2.0 * *(1.2-3.1)$ & $0.9(0.5-1.8)$ & $2.0 *(1.1-3.4)$ & - \\
\hline CAGE: positive for drugs or alcohol & $1.6(0.96-2.7)$ & $2.6^{*}(1.2-5.4)$ & - & $1.6(0.8-3.4)$ \\
\hline
\end{tabular}


The USA has a highly developed system of 'drug courts' and, more recently, 'mental health courts' ${ }^{15}$ exclusively trying and sentencing individuals with behavioural and mental health problems. England utilises a range of 'court diversion' schemes where individuals are identified pre-trial and diverted into the healthcare system. In the USA the coercion is explicit in the sentencing procedure -'choose treatment or punishment'. The less formal English approach may mean that potential coercion is not registered.

The most striking difference between the two national samples is in the use of money as leverage. Over half of the US sample $(n=519)$ had a financial guardian or someone unofficially managing their money. Of these, 121 (32\%) participants reported that receiving it had depended on their accepting treatment. In the English sample, 165 (40\%) reported that they had someone managing their money but only $10(6 \%)$ experienced it as leverage. Money management remains a controversial issue in England and few teams use it or feel comfortable with it. Half $(n=5)$ of those reporting it were in the substance misuse group and presumably this was family pressure as the clinical teams did not use it. Some AOTs in England are now experimenting with its use. $^{16}$

\section{Baseline characteristics associated with leverage}

We failed to find the strong association between leverage and patient characteristics as in the USA, probably because of their larger sample and greater clinical variation. Our only significant associations were with a substance misuse diagnosis, more than two hospitalisations and a lower score on the insight and treatment attitudes measure (ITAQ).

\section{Limitations}

Our study has several limitations. It reports 'experience' of leverage without third-party corroboration. Some of the leverages reported would probably have been disputed by the clinicians. Leverage may also have been applied but not recognised as such. Szmukler \& Appelbaum have outlined a gradation of informal coercion and many staff may strive to recast leverage as persuasion. ${ }^{17}$ We were also obliged to use differing sampling strategies for the different teams but it is unclear what effects this would exert. Our refusal rate is also more than twice that in the US sample (31\% compared with $2-15 \%)$. The reasons for this are unclear and it cannot be discounted that participants perceiving higher levels of coercion might be more likely to refuse, thereby reducing the reported English levels. Higher levels of leverage were demonstrated to be associated with committed acts of violence (18-21\% in the preceding 6 months) in the US sample. ${ }^{18}$ In the absence of comparable violence data in the English sample we cannot estimate if it might account for the reported leverage differences. We are unable to draw any conclusions as to the efficacy of leverage in this cross-sectional study.

\section{Implications}

Despite these limitations we believe our results convey a broadly accurate picture of the experience of leverage in these patient groups. In the mental illness groups leverage rates are associated with increasing severity of illness. The high levels in substance misusers reflect a tougher negotiating approach to individuals generally perceived to have more control over their behaviour. English staff assume that severely ill individuals are 'entitled' to a wide range of social benefits (housing, financial support, etc). In the USA, benefits are rarely viewed as automatic entitlements, but are targeted where most likely to achieve effect. The participants in the US study were, however, generally in receipt of these benefits and it is possible that higher reported perceived coercion may reflect the more widespread sense of entitlement in the English sample rather than any higher actual leverage in the US sample.

Overall, the pattern is more similar than different between the USA and England. A substantial proportion of individuals in public mental healthcare do not feel entirely free in their interactions with services. Although some pressure comes from family and friends, many experience healthcare staff as coercing them. Informal coercion is as widespread, if not more so, than formal coercion. There is a pressing need for research to understand it both to inform policy and to train staff who are clearly using it routinely.

\footnotetext{
Tom Burns, MD, DSC, FRCPsych, Department of Psychiatry and Social Psychiatry Unit, University of Oxford, Oxford, UK; Ksenija Yeeles, BSC, Andrew Molodynski, MBChB, MRCPSych, Helen Nightingale, BA, Social Psychiatry Unit, Department of MBChB, MRCPSych, Helen Nightingale, BA, Social Psychiatry Unit, Department
Psychiatry, University of Oxford, UK; Maria Vazquez-Montes, BSc, MSc, PhD, Department of Public Health and Primary Care, University of Oxford, UK; Kathleen Sheehan, MD, DPhil, Department of Psychiatry, University of Toronto, Canada; Louise Linsell, MSc, Department of Public Health and Primary Care, University of Oxford, UK

Correspondence: Tom Burns, MD, DSC, FRCPsych, Department of Psychiatry, University of Oxford, Warneford Hospital, Oxford OX3 7JX, UK. Email: tom.burns@ psych.ox.ac.uk

First received 8 Sep 2010, final revision 11 Jan 2011, accepted 23 Feb 2011
}

\section{Appendix}

\section{Questions used to identify experienced leverage}

Finance

Did anyone (financial manager/guardian) ever make giving you your money, or giving you spending money, depend on whether you did what he or she wanted in terms of getting mental health, alcohol or drug treatment (or taking medication)?

\section{Housing}

Have you ever lived somewhere where you were required to stay in mental health or substance use treatment (or required to continue taking your medication) to keep living there (including family home)?

Have you ever been told that obtaining new accommodation is dependent on you taking treatment?

\section{Criminal justice}

Has anyone in the legal system ever told you or your lawyer that the charges will be dropped or reduced if you get treatment in the community for your mental health, alcohol or drug problems?

Has a mental health professional, or anyone in the legal system, or their report, suggested that you take treatment for a mental health problem as a condition of not going to prison?

\section{Child custody}

Have you ever been told that your children might be taken into care if you did not participate in mental health, alcohol or drug treatment (or taking your medication)?

Have you ever been told that your access to see your children would be reduced if you did not participate in mental health, alcohol or drug treatment (or taking your medication)?

\section{References}

1 Kjellin L, Hoyer G, Engberg M, Kaltiala-Heino R, Sigurjonsdottir M. Difference in perceived coercion at admission to psychiatric hospitals in the Nordic countries. Psychiatr Epidemiol 2006; 41: 241-7. 
2 Dawson J. Community Treatment Orders: International Comparisons. Otago University, 2005

3 Hoge SK, Lidz CW, Eisenberg M, Gardner W, Monahan J, Mulvey E, et al. Perceptions of coercion in the admission of voluntary and involuntary psychiatric patients. Int J Law Psychiatry 1997; 20: 167-81.

4 Monahan J, Redlich AD, Swanson J, Robbins PC, Appelbaum PS, Petrila J, et al. Use of leverage to improve adherence to psychiatric treatment in the community. Psychiatr Serv 2005; 56: 37-44.

5 Clark Robbins P, Petrila J, LeMelle S, Monahan J. The use of housing as leverage to increase adherence to psychiatric treatment in the community. Admin Policy Ment Health 2006; 33: 226-36.

6 Redlich AD, Steadman HJ, Clark Robbins P, Swanson JW. Use of the crimina justice system to leverage mental health treatment: effects on treatment adherence and satisfaction. J Am Acad Psychiatry Law 2006; 34: 292-9.

7 Endicott J, Spitzer RL, Fleiss JL, Cohen J. The Global Assessment Scale. A procedure for measuring overall severity of psychiatric disturbance. Arch Gen Psychiatry 1976; 33: 766-71.

8 Overall JE, Gorham DL. The Brief Psychiatric Rating Scale. Psychol Rep 1962 10: 799-812.

9 McEvoy JP, Freter SMS, Everett G, Geller JL, Appelbaum P, Apperson LRL. Insight and the clinical outcome of schizophrenic patients. J Nerv Ment Dis 1989; 177: 48-51.
10 Erwing JA. Detecting alcoholism. The CAGE questionnaire. JAMA 1984; 252 1905-7.

11 Hox J. Applied Multilevel Analysis. TT-Publikaties, 1995

12 World Health Organization. The ICD-10 Classification of Mental and Behavioural Disorders: Clinical Descriptions and Diagnostic Guidelines. WHO, 1992.

13 Busch A, Redlich A. Patients' perception of possible child custody or visitation loss if not adherent to psychiatric treatment. Psychiatr Serv 2007; 58: 999-1002.

14 Swartz MS, Swanson JW, Kim M, Petrila J. Use of outpatient commitment or related civil court treatment orders in five U.S. communities. Psychiatr Serv 2006; 57: 343-9.

15 Redlich AD, Steadman HJ, Monahan J, Robbins PC, Petrila J. Patterns of practice in mental health courts: a national survey. Law Hum Behav 2006; 30: $347-62$.

16 Burns T, Firn M. Assertive Outreach in Mental Health: A Manual for Practitioners. Oxford University Press, 2002.

17 Szmukler G, Appelbaum P. Treatment pressures, leverage, coercion and compulsion in mental health care. J Ment Health 2008; 17: 233-44.

18 Swanson JW, Van Dorn RA, Monahan J, Swartz MS. Violence and leveraged community treatment for persons with mental disorders. Am J Psychiatry 2006; 163: 1404-11. 